\title{
O exemplo de Agrado: imagem, técnica e autenticidade
}

\section{The example of Agrado: image, technics and authenticity}

\author{
Wenceslao Machado de Oliveira $\mathrm{Jr}^{*}$ \\ (...) se é mais autêntica quanto mais se parece \\ com o que se sonhou para si mesma...
}

Agrado - no palco do teatro

\begin{abstract}
RESUMO
Tomando como referência a personagem Agrado do filme Tudo sobre minha mãe, de Pedro Almodóvar, ensaiam-se proposições sobre um outro modo de se entender a autenticidade - desvinculado da natureza dos corpos e vinculando-se à cultura urbana e às técnicas que vêm permitindo aos corpos a realização material de um vir-a-ser sonhado - de uma imagem para o corpo. De que maneira o cinema, a partir dos exemplos dados pelos personagens apresentados em suas telas, atua na produção dessas imagens-corpos? A educação do olhar pelas imagens cinematográficas permitiria uma visão para além da imagem? Essas são as perguntas que perpassam o ensaio.

Palavras-chave: cinema, corpo, autenticidade, técnica, educação do olhar.
\end{abstract}

\begin{abstract}
Taking the character Agrado, from the Pedro Almodovar's movie All about my mother, the author essays some propositions about another way to understand the authenticity of an image for the human body - unlinked from the nature and attached to the urban culture and to the technology

* Faculdade de Educação, Universidade Estadual de Campinas (Unicamp).Laboratório de Estudos Audiovisuais-OLHO. E.mail: wences@unicamp.br
\end{abstract}


that have been allowing the materialization of the dreamed body to anyone. In which way do the movies, and the examples provided by their characters showed at the screen, act to produce these body-images? Does the eye education by movie pictures allow a vision beyond the image? These are the questions proposed in this essay.

Key-words: movie pictures, body, authenticity, technique, education of seeing.

É possível que uma personagem cinematográfica venha para indicar alguma radicalidade na produção contemporânea dos corpos? Haveria indícios de alterações significativas na noção de autenticidade contidas em palavras, gestos e revelações na personagem Agrado? As palavras dela sobre o próprio corpo, como uma narrativa de sua vida, estariam a nos propor uma autenticidade desligada de origem e formação - nascimento, biologia, personalidade e remetida a um vir-a-ser - sonhos, técnica, imagem?

Com essas perguntas peço ao leitor que se debruce sobre os parágrafos seguintes. A partir delas, escrevi este ensaio. Quero desde já avisar que fiz inúmeros apontamentos a partir da curta seqüência cinematográfica em que a personagem travesti conta sua história, mas é provável que estejam um tanto soltos, dispersos, pouco alinhavados, e assim este ensaio vai se constituir de alguns saltos entre os comentários mais diretamente ligados ao corpo-imagem-palavra da personagem Agrado $^{1}$ e incursões outras sobre cinema - tomado como linguagem e fenômeno cultural contemporâneo. Haverá ainda alguns silêncios, marcando vazios nos entendimentos que estou a perseguir. Quem sabe vocês acabem por preenchê-los com sua leitura.

Começo apresentando a citação de Pier Paolo Pasolini que me sugeriu o título:

A série de informações que um homem dá por si próprio enquanto realidade representando-se e agindo chama-se, por fim, exemplo: e esta é a diferença entre a linguagem da realidade natural e a da realidade humana. A primeira não dá mais do que informações, a segunda, ao mesmo tempo que as informações, dá o exemplo (PASOLINI, 1982, p. 108). 1999).

Agrado é personagem do filme Tudo sobre minha mãe de Pedro Almodóvar. (Espanha, 
O cineasta italiano toma o cinema como língua escrita da realidade que tem os seus signos - imagens e sons - captados diretamente do real. Os escritos dele, propositivos de uma maneira de pensar o cinema, são minha base teórica, imaginativa. A partir deles e com eles, deverei construir minha escrita sobre as narrativas audiovisuais.

Seguindo o curso das minhas divagações, continuo, com Pasolini:

A linguagem da realidade, enquanto era apenas natural, estava fora de nossa consciência: agora que surge "escrita" através do cinema, não pode deixar de encontrar-se com uma consciência. A linguagem escrita da realidade, far-nos-á saber, antes de tudo o mais, o que é a linguagem da realidade; e acabará por finalmente modificar o nosso pensamento diante dela, tornando as nossas relações físicas, pelo menos, com a realidade, relações culturais (PASOLINI, 1982, p. 191-192).

As proposições de Pasolini chegaram e sentaram-me ao meu lado no sofá, ${ }^{2}$ enquanto eu via e ouvia Agrado. As imagens e ironias da personagem me diziam muitas coisas. Entendi: o cinema dá consciência de que sou um corpo, enquanto na narrativa escrita posso prescindir dessa imagem corporal.

Antes de prosseguir com meus pensamentos, gostaria de apresentar a escolhida seqüência do filme Tudo sobre minha mãe.

A câmera desliza sobre as cortinas vermelhas fechadas e as luzes se acendem num foco no meio do palco, onde Agrado está de pé. Ela pede desculpas pela ausência das duas atrizes daquela noite dizendo que, aos que não tenham nada mais pra fazer, poderia contar a história de sua vida. Após a saída de algumas pessoas da platéia, Agrado inicia sua fala entre irônica e sarcástica, completada por um gestual ambíguo. "Me chamam Agrado, porque toda minha vida só fiz agradar às pessoas. E, além disso, sou muito autêntica. Olhem que corpo!!" Faz uma pausa e aí começa a apontar as partes de seu corpo onde as transformações sonhadas por ela se realizaram por meio de inúmeras intervenções cirúrgicas. A cada parte apontada, corresponde o valor da respectiva cirurgia: "Peitos. Dois, porque não sou nenhum monstro. Oitenta mil cada... mas já bastante amortizados." A cena termina com esta fala de

2 Aqui estou me reportando a Clarice Lispector, quando escreve Entendimento: "Todas as visitações que tive na vida, elas vieram, sentaram-se e não disseram nada" (1992, p. 145). 
Agrado: "Não devemos economizar, pois se é mais autêntica quanto mais se parece com o que se sonhou para si mesma." Esta seqüência fecha-se com um close no rosto da personagem que ainda mantém seu olhar engraçado mas que agora também parece esperar a aprovação da platéia. Aplausos.

Pois bem, vamos àquilo que as imagens mobilizam em mim, volto aos meus pensamentos.

Temos aí, nesta seqüência assistida por muitos e aqui resumida brevemente, um corpo a impressionar a retina. Pois é neste corpo da personagem Agrado que devo me concentrar. Lembro a idéia de Pasolini de que a realidade humana nos dá, além de informações, o exemplo.

Agrado não fala do sexo, do seu corpo-intimidade, Agrado traz o seu corpo-imagem como exemplo de autenticidade.

Discuto então esta construção imagética acerca do que seja o feminino e o masculino que, no meu entender, têm (na imagem do) corpo físico o seu lugar privilegiado de concretização. Lembro antes Milton Almeida, quando escreve (...) “ a interpretação (de qualquer obra audiovisual) deve ser verbal e visual ao mesmo tempo" (ALMEIDA,1999a, p. 13). É ele também quem diz que o cinema e a televisão realizam:

... um processo de educação cultural da inteligência visual cuja configuração estética é, ao mesmo tempo, uma configuração política e cultural e uma forma complexa do viver contemporâneo permeado de representações visuais. (...) Uma arte que, em forma plástica, dá visibilidade estética a um momento social, político, enquanto constrói e reconstrói a memória deste momento (ALMEIDA, 1999a, p. 10).

Há muitas semelhanças entre cinema e tevê, principalmente no que se refere à estruturação das duas linguagens em cenas e seqüências audiovisuais. A diferença mais importante que percebo, no entanto, está no plano da recepção destas imagens e sons, o que, ao meu ver, repercute na subjetividade, atuando de maneira decisiva no jeito como essas imagens e sons são vivenciados pelas pessoas. $\mathrm{O}$ cinema manifesta uma exibição ritualizada (constrói um tempo e um espaço outros para sua recepção), ao contrário da tevê: quando vemos um filme no cinema estamos mais disponíveis a nos relacionarmos com os personagens, ou seja, nós os espiamos com mais intensidade e profundeza, assim como eles igualmente nos es(x)piam (às nossas culpas, aos nossos gestos, às nossas durezas e fragilidades) - o que penso não ocorre com a tevê. 
Penso que as subjetividades contemporâneas (notadamente aquelas em formação - de crianças e jovens) têm na imagem do corpo físico um de seus pontos centrais, senão o seu centro único. E é este corpo que o cinema (e a tevê) nos exibem quase o tempo todo, exaustivamente, de maneira fragmentada (mãos num momento, pés em outro, músculos em outro, face em outro...), deixando aos espectadores a tarefa de reagrupar, juntar, organizar esses fragmentos corporais em seu imaginário.

O cinema não apenas representa a realidade, mas a apresenta diante de nós, dando a ela existência, ao propor um real. Tentando estabelecer um paralelo com a literatura, chamo Clarice Lispector, em sua "A pesca milagrosa":

Então escrever é o modo de quem tem a palavra como isca: a palavra pescando o que não é palavra. Quando essa não-palavra morde a isca, alguma coisa se escreveu. Uma vez que se pescou a entrelinha, poderse-ia com alívio jogar a palavra fora. Mas aí cessa a analogia: a nãopalavra, ao morder a isca, incorporou-a (LISPECTOR, 1992, p. 34).

Assim também é com as imagens no cinema. Ao inscrever na tela parcelas da realidade, o cinema traz para aí o inconcluso, a ambigüidade, a mistura, o conflito, os intervalos de que este real está prenhe. ${ }^{3}$

O cinema nos apresenta uma aparência-que-é, e nela assimilou-se (incorporou-se) o sentido, a entrelinha, a realidade. Na imagem-corpo da personagem configura-se esse amálgama complexo. Ao se colocar diante da tela, o espectador assiste a ele e dele se apropria.

Num mundo onde as imagens circulam com facilidade e se destacam como o centro dos discursos (das narrativas), o conselho, dado em palavras pelo narrador-literato, foi substituído pelo exemplo, dado pelo corpo-palavra do personagem audiovisual. ${ }^{4}$ Pois será no cenário dessa mudança radical que caracteriza nossa vida cultural e política que tentarei desenvolver os meus pensamentos sobre Agrado, a personagem de Almodóvar.

3 Para capturá-lo sem nos prendermos exclusivamente ao que a imagem nos mostra, deveríamos seguir o ensinamento da mesma Clarice, concluindo a citação acima: “(...) O que salva então é ler 'distraidamente'." (LISPECTOR, 1992, p. 34).

4 Laura Coutinho, ao aproximar as idéias de Walter Benjamin das de Pasolini, escreve: "As narrativas contemporâneas, sobretudo as mais populares, embora não prescindindo da fala, colocam ênfase na imagem. O exemplo assume assim o lugar do conselho" (COUTINHO, 2001, p. 38). 
Primeiro, discuto a escolha, pelo diretor e sua equipe, da pessoa que interpretaria a personagem Agrado. Alguém a teria indicado ao diretor. Ela era dançarina de um cabaré. Ele foi vê-la dançar (atuar) e aprovou sua "imagem geral". Aí vieram os testes mais específicos de atuação cinematográfica e a decisão de que seria ela mesma a escolhida. Daí em diante a transformação dessa "imagem geral" na imagem imaginada pelo diretor: o ajustamento do corpo da atriz ao da personagem. Para atender à expectativa do filme, a atriz precisou emagrecer uns 8 quilos...

A personagem imaginada pelo diretor visava uma certa representação. Mas a atriz, ${ }^{5}$ ao ter sua imagem-corpo impressa na película e projetada na tela, mais do que representar, coloca-se como uma apresentação: é a si mesma que se nos apresenta, enquanto corporeidade e imagem, como um exemplo do feminino, presente em seu corpo de mulher. ${ }^{6}$

Escolhi trazer justamente esta personagem, a imagem-corpo de Agrado, porque ela, ao contrário da infinita maioria das personagens de cinema e tevê, parece propor um novo olhar para os corpos - vindo para propiciar um desassossego - associando a si mesma algo que estaria em nossa tradição cultural no seu extremo oposto: a autenticidade. Em nossa cultura, via de regra, a noção de autenticidade está vinculada à idéia de persistência das nossas origens - biológicas e psicológicas - ao longo da vida. Essa idéia vem associada, em grande medida, à proposição de que devemos ser coerentes. Ao usarmos essas origens como parâmetro é que essa coerência seria alcançada.

Agrado, ao contrário, depois de nomear e enumerar um sem número de cirurgias que tornaram o seu corpo, antes próximo da imagem do masculino, um corpo conectado à imagem do feminino, afirma que todas essas intervenções corporais foram feitas com o intuito de apresentá-la como uma imagem autêntica.

Notem que a personagem vem propor uma idéia de autenticidade cada vez mais exeqüível em nossa sociedade em que os recursos tecnológicos de todo tipo se fazem mais e mais presentes a cada dia (e aqui incluo não só as cirurgias, mas também todo o aparato das academias de ginástica e da indústria dos cosméticos e dos hormônios). Uma autenticidade, eu diria, urbana, específica do ambiente técnico no qual vivemos hoje. Uma autenticidade que vincula os (corpos de) homens e mulheres não mais (e somente) à natureza, mas principalmente à história e à cultura.

5 A personagem Agrado é interpretada pela atriz espanhola Antonia San Juan.

6 Se como mulher a atriz nos apresenta um exemplo do feminino, como personagem ela nos apresenta um exemplo do travestismo. Tensão e ironia postas no corpo diante de nós na tela e no palco do teatro. 
A construção de imagens-corpos se dá tanto nos acessórios que colocamos sobre o corpo, quanto naqueles que colocamos nele, a pele como limite e interface entre o que está sobre e o que está dentro. Aquilo que é inserido no dentro, por ser entendido como conteúdo interno corporal, deixa de ser (pensado como) acessório.

Essa situação se dá porque acreditamos (e em grande medida se confirma na maioria das vezes) que os acessórios externos têm uma temporalidade de convivência (e atuação sobre nós mesmos) pequena e/ou esporádica, enquanto aqueles que inserimos sob nossa pele (como um bíceps muito desenvolvido por exercícios numa academia de ginástica) têm uma temporalidade mais longa, contínua. ${ }^{7}$

Com as sofisticações tecnológicas dos processos de intervenção no corpo, essas temporalidades ficam ainda mais tensionadas, desde que é possível colocar e tirar silicone ou carne ou fios de ouro quase com tanta rapidez quanto se faz crescer os cabelos com o megahair ou se troca de figurino para se deslocar de um evento a outro.

No Brasil, somos recordistas mundiais nessas intervenções corporais internas significando, possivelmente, que vivemos numa cultura bastante permissiva, a aceitar a autenticidade corporal (subjetiva) sob outros princípios que não aqueles da naturalidade das origens. O que essas estatísticas manifestam é que a proposição de Agrado - a autenticidade alcançada na subversão mesma do natural-corporal-original - parece ser muito bem aceita entre os brasileiros.

Mas notem, esses brasileiros e brasileiras, sofreram intervenções na imagem e no corpo, enquanto a personagem Agrado apenas passou por alterações em sua imagem (adiante falaremos com mais vagar dessa distinção). A personagem não fala do sexo, do seu corpo-intimidade, Agrado fala do seu corpo-imagem... Aqui é bom lembrar de Ismail Xavier: (...)“a montagem sugere, nós deduzimos" (XAVIER, 1988, p. 368). O quê? Deduzimos virilidade, maciez, força, alegria, suavidade, desejo, a partir do corpo que se apresenta diante de nós. Vale tanto para o cinema, quanto para a realidade do dia-a-dia, se concordamos ser o primeiro a língua escrita da segunda.

7 Entretanto me parece que, contemporaneamente, isto não é tão verdadeiro assim, uma vez que posso passar minha vida toda usando roupas de grife ditadas pela última moda (o que significa uma temporalidade longuíssima, a despeito de cada peça em particular ter sido usada uma ou duas vezes no máximo) enquanto posso ter tendência a engordar e, quando tenho energia, faço "dietas de fome", o que me leva a ficar seis meses gordo e seis meses magro, a cada ano... uma temporalidade bem menor. 
A diferença fundamental é que o cinema, nas palavras já citadas de Pasolini, propicia a consciência da realidade. Penso que essa consciência, na contemporaneidade, já se deu, ao realizarmos a idéia de Pasolini: nossas relações físicas com a realidade tornaram-se, sim, relações culturais, pois tomamos consciência da linguagem da realidade, da linguagem dos corpos e hoje nos olhamos assim, sabedores de que somos o produto de autenticidades e falseamentos. ${ }^{8}$

Falseamentos que a própria personagem de Almodóvar revela, por ser uma mulher desempenhando o papel de um travesti, quando, para sê-lo "verdadeiramente" teria que ter nascido homem. [Ou não? Nos mutantes e fluidos papéis e orientações de nossa sexualidade, já podemos encontrar alguém que, nascida mulher, tornou seu corpo (não somente sua imagem) masculino, ao incluir nele um pênis, e assumiu como profissão ser travesti, mantendo para isto os seios].

Ao que me parece, as pessoas não intervêm em seu corpo-intimidade, mas no corpo-imagem pois, de maneira geral, devem estar satisfeitos com seu sexo de origem. Mas não tão satisfeitos com sua sexualidade... Tomo sexualidade como algo maior e multifacetado do que o sexo. Na sexualidade está incluído todo o corpo, além do ambiente no qual ele vive e para onde dirige seus desejos. Texturas, músicas, perfumes, sabores e cores. Tudo é sexualidade e tudo sobre ela atua, em todos os sentidos, tanto no plano físico quanto no plano simbólico.

Acima de tudo penso que nossa sexualidade é construída sobre o altar da imagem visual do corpo físico (tanto do nosso próprio quanto dos outros). E seria por esta razão que precisamente nesta imagem-corpo temos buscado intervir. Assim, parece-me claro que nos meios imagéticos de comunicação (cinema, tevê, fotografia, propaganda) estariam as mais fortes mediações sobre nossas imagens corporais.

É bem verdade que a cada dia há um maior número de imagens corporais sendo veiculadas e que dessa forma amplia-se, igualmente a cada dia, o

8 Ao reconhecer a linguagem audiovisual como aquela na qual este (nosso) mundo urbano se expressa, podemos dizer que perdemos a inocência de nossas experiências cotidianas de olhar e ouvir. São essas experiências, provenientes de nossos corpos em ação no mundo, que poderão ser apropriadas (utilizadas por nós próprios ou outros) como signos de uma narrativa audiovisual. Além disto, com certeza são estas mesmas experiências corporais que nos permitem e permitirão um entendimento das narrativas audiovisuais que só se tornam inteligíveis ao cruzarmos as imagens e sons que vemos na tela com nossas memórias da oralidade vivida desde o nascimento, configuradas estas em inúmeras experiências de olhar e ouvir... e agir. Assistimos cinema e tevê em reminiscências - usando a memória e fazendo alusões - daí que se torna ampliado o peso e o valor dessas experiências passadas e presentes. 
número de modelos disponíveis no mercado. Gerados por uma crítica aos modelos padronizados, nos quais poucos corpos concretos poderiam se ajustar, estes novos modelos, ao invés de nos libertar, vêm trazer, por meio das influências das mídias, aqueles corpos que delas se encontravam alijados por sua impossibilidade material de assumir algum daqueles padrões, antes em menor número. ${ }^{9}$

É importante lembrar que essas imagens corporais internalizadas como nossos modelos acabam por impregnar nossos corpos, legando-nos jeitos, formas, expressões faciais, gestos, ainda que o tempo de convivência de nossos corpos com esses modelos tenha sido breve.

Essa situação caracteriza um clima de aprisionamento pelo mercado que é aquela tensionada ironicamente na aparição e nas falas das personagens do filme de Aldomóvar. O próprio título do filme, Tudo sobre minha mãe, é uma ironia sobre nossas concepções de maternidade-paternidade, uma vez que nomeia uma história sobre a mãe para nos falar do pai. ${ }^{10}$ Melhor dizendo, o diretor consegue uma tensão entre os papéis representativos de "pai" e "mãe", mediante uma apresentação ambígua das imagens de mulher e homem - fazendo eco, tal proposição, numa sociedade em que a imagem e a cultura têm superado, em muitas e variadas situações, a biologia e a natureza.

Especialmente a personagem Agrado expressa essa ironia, porque ela diz com seu corpo de atriz-mulher de um conteúdo que deve ser entendido a

9 Nos dias atuais já são veiculados modos corporais de ser negro, gordo, feio, pobre, gay, faxineiro, boiadeiro, entre outros tantos outros personagens-tipo presentes em nossas telas e telinhas. Nesse sentido, aparece um "detalhamento" daquilo que venho discutindo neste ensaio. Com os filmes, programas e novelas "temáticos" da atualidade, são muitos os personagens que nos apresentam vários modos de ser e de agir - vestir, falar, sentar, andar, olhar, etc... Por sua vez, esses modos vêm associados a tipos específicos de personalidade: boiadeiro-tímido, boiadeiro-destemido, boiadeiro-engraçado, boiadeiro-baixo, boiadeiro-alto, boiadeiro-gay, boiadeiro-apaixonado, boiadeiro-cabeludo, boiadeiro-negro, etc... Subdivisões de uma categoria para melhor atender (e enquadrar) a todas as pessoas que desejam configurar sua imagem-corpo na imagem apresentada de um boiadeiro.

${ }^{10}$ Este pai é o genitor biológico do jovem e do recém-nascido - ambos batizados com seu nome, Esteban - que aparecem no filme. Ele é o personagem Esteban/Lola (representado pelo ator Toni Cantó). Trata-se aqui de um homem que tornou sua imagem-corpo mais próxima à de uma mulher, a partir da inserção neste corpo, originalmente masculino, de seios, cabelos longos, roupas femininas. Este personagem foi casado com a personagem principal da trama, a personagem Manuela (representada pela atriz Cecília Roth) e, depois das intervenções cirúrgicas para se apresentar como mulher, escolheu como profissão, a prostituição. Entretanto, conservou seu pênis, com o qual manteve relações sexuais, gerando filhos com duas das protagonistas do filme, Manuela e Rosa (representada pela atriz Penélope Cruz). No limite da apresentação da sua imagem corporal, o personagem-pai Estéban é também personagem-mãe, Lola. 
partir da imagem de um corpo travesti-homem que manifesta, cruzados em si, formas e desejos tanto femininos como masculinos. Essa situação é revelada ao espectador em cena onde um homem (personagem secundário na trama) pede a Agrado que lhe faça “(...) um boquete". ${ }^{11}$ Diante do homem perplexo, ela retruca, dizendo a ele: “(...) Por que você não pergunta se eu também desejo um!"

Voltando à cena na qual Agrado está no palco a contar sua história, notamos pelas palavras da personagem que, em seguida à autenticidade - "sou muito autêntica" - vem o corpo - "olhem que corpo!" A autenticidade, por sua vez, vem ligada - se é mais autêntica - à imagem e ao futuro - quanto mais se parece com o que sonhou de si mesma. Não mais o corpo-sexo-origem, o passado como referência para a autenticidade. Em seu lugar está um vir-a-ser, a possibilidade de tornar exterior uma imagem que até então fora somente interior.

Neste caso, essa "imagem interior" não mais seria aquela elaborada pelos processos psicológicos próprios da subjetivação. A imagem interior em especial seria, nesse contexto, aquela considerada racional e pragmaticamente como a melhor, (o que significa) a imagem melhor habilitada, por sua eficácia, a se tornar pública - exteriorizada. Portanto, será essa a imagem construída por cada um em torno das idéias de produtividade, competitividade e padrões instituídos de beleza e sedução. Idéias oriundas dos raciocínios econômicos mercantis que mediam as maneiras de como nos tornar suficientemente atraentes para o mercado.

Dito de maneira mais radical, indicada pela própria personagem Agrado, o parâmetro de construção de nossa imagem vem sendo aquele de nos tornar reserva de mercado, disponíveis para consumo, construídos para agradar.

Uma vez que a "imagem interna" tem a potencialidade técnica de se desdobrar sobre nossa pele e exteriorizar-se em nosso corpo, a construção do si-mesmo, de nossos corpos, se daria como imagem-corpo pra agradar a um outro. Esse outro, por sua vez, pensado como consumidor, portanto um outro percebido em quantidade e indiferenciação. Não importa Quem, importando quantos.

Então Agrado, prostituta de profissão, tornara seu corpo um bem de produção. Assim seus seios podem ser "amortizados", uma vez seu preço ter sido recuperado em função de sua utilização na produção de prazeres (e ren-

11 Termo da oralidade popular para designar a felação. 
da) por seu trabalho. Nossos esforços e custos pra transformar nosso corpo em consonância com essa "imagem interior" podem ser igualmente pensados em termos econômicos de amortização, desde que sejam contabilizadas nossas conquistas - olhares, beijos, transas, paqueras, relacionamentos (comportamentos amorosos em geral); o mesmo procedimento utilizado com o dinheiro.

Nossa tradição recente de imagens visuais tem moldado nossos corpos (de fora para dentro) da mesma forma como são moldados músculos e nervos e ossos (de dentro para fora). O cinema, a nos dar a visibilidade, deu-nos também a consciência dos nossos corpos em gestos, expressões e movimentos. Ao educar nosso olhar a reconhecer o corpo como lugar de controle e possibilidade, o cinema dota esse olhar de uma potência nunca sonhada por nossos antepassados históricos.

Numa situação de paquera, da aproximação com o olhar, passamos para outras aproximações, com o ouvido, o nariz, as mãos e pele, até chegarmos à boca, prenúncio de intimidades outras. Do olhar ao gosto, o que nos acontece é um mergulho no outro.

Entretanto, fora dos ambientes onde essas aproximações são legitimadas, vivemos habitualmente nos limites da distância oferecida pelo outro, o que faz com que o olhar crie sutilezas para reconhecer o que ou quem se dispõe a ser visto. $\mathrm{O}$ reconhecimento pelo olhar se faz a partir de indícios, os quais, à medida que se tornam perceptíveis à consciência, nos permitem reconhecer com mais acuidade as características de quem está diante de nós. Ao mesmo tempo, temos a possibilidade de manipular nós mesmos os indícios que decidirmos serão observados por ou escondidos do outro.

Reitero que é o cinema (e seus corolários imagéticos) que propicia a acuidade e a aprendizagem indispensáveis ao reconhecimento destes indícios, ao mesmo tempo em que revela a facilidade com que podemos ser enganados pelo olhar. Por isso, a cada passo no caminho dos jogos do olhar corresponde um passo no aprimoramento das suas sutilezas. Se Agrado revela sua vida, sua imagem aos olhares da platéia, seu corpo, por sua vez, só é revelado em situações privadas, quando alguma intimidade já se fez entre as pessoas-personagens.

Um exemplo é apresentado naquele momento em que Agrado revela a outro personagem do filme ${ }^{12}$ (bem como ao público do cinema) a existência de um pênis em seu corpo-imagem feminino. Existência declarada em um

${ }^{12}$ Lembrando: o homem que lhe pede um boquete. 
momento de privacidade - e assim de alguma intimidade - em cena tensa, onde Agrado surge quase hostil. A existência do mesmo pênis é omitida quando da apresentação pública do corpo-imagem de Agrado à platéia do teatro.

O cinema, portanto, em paradoxal movimento, ao mesmo tempo que amplia nossa percepção do outro, nos coloca perante nossos limites em relação a sua intimidade. É dessa forma que as imagens cinematográficas prosseguem com a educação do nosso olhar propondo, de maneira peculiar, modos de convivência com exemplos desses novos corpos que realizam, exercitam e vêm propiciar a constituição de outras formas de subjetividade.

Diria mesmo que o cinema nos traz tranqüilidade com seus exemplos, justamente quando o próprio cinema, como narrativa, constrói imagens dos corpos humanos revelando apenas o que é do seu agrado ${ }^{13}$ (daquela narrativa ou momento da narrativa). Desse modo, cada filme se permite persuadir os espectadores a criarem entendimentos e desejos que não mais se vinculem àquela idéia de autenticidade como submissão à natureza, mas a uma outra autenticidade, mais urbana e performática, enquanto componente de um jogo social disponível a partir de suas possibilidades técnicas e culturais.

Tentei, neste ensaio, apontar o cinema como uma poderosa técnica de inventar corpos que, associada a outras tecnologias contemporâneas, tem trazido para nossa convivência a presença de outros corpos e, portanto, de outras possibilidades de subjetivação.

Finalizo eu também pedindo aplausos para Agrado. Afinal, essa personagem expõe com clareza cristalina a proposta de autenticidade de uma civilização que já dispõe de tecnologia para pensar os corpos como parte intrínseca da cultura - e não da natureza. Sua proposição de autenticidade liberta-nos das limitações de origem que a linguagem (a realidade) da natureza traz, colocando nossos corpos sob as possibilidades da linguagem (da realidade) $h u$ mana, onde as informações são também exemplos e, as temporalidades, mais fluidas e flexíveis.

(Que tal, lentes azuis para o programa de hoje à noite? Um sutiã com enchimento? Ou então, uma bota masculina com salto interno, que me deixaria de seis a oito centímetros mais alto sem que as pessoas a minha volta percebessem o artifício? Para o próximo ano, quem sabe, seios maiores e uma bunda mais redonda...)

${ }^{13} \mathrm{O}$ mesmo acontece com a personagem de Almodóvar ao revelar ao público tão somente o que lhe convém: sua imagem-corpo, negando-lhe seu corpo-intimidade. Uma justificativa mais do que razoável para o nome escolhido para a personagem, ultrapassando a primeira camada de compreensão possível, de que seu nome seria devido à necessidade da personagem de agradar os outros. Agrado seria assim uma metáfora do cinema. 


\section{REFERÊNCIAS}

ALMEIDA, M. J. de. A educação visual da memória: imagens agentes do cinema e da televisão. Pro-posições, Universidade Estadual de Campinas, Faculdade de Educação, v. 10, n. 2, p. 29, jul. 1999a.

ALMEIDA, M. J. de. Cinema - arte da memória. Campinas: Autores Associados, 1999b.

COUTINHO, L. O estúdio de televisão e a educação da memória. Campinas, 2001. Tese (Doutorado em Educação) - Faculdade de Educação, Universidade Estadual de Campinas.

LISPECTOR, C. Para não esquecer. São Paulo: Siciliano, 1992.

PASOLINI, P. P. Empirismo herege. Lisboa: Assírio e Alvim, 1982.

PASOLINI, P. P. Gennariello: a linguagem pedagógica das coisas. In: . Os jovens infelizes. São Paulo: Brasiliense, 1990.

XAVIER, I. Cinema: revelação e engano. In: NOVAES, A.(Org). O olhar. São Paulo: Cia. das Letras, 1988.

Texto recebido em 07 fev. 2005

Texto aprovado em 09 abr. 2005 